\title{
vol.3 No.1 ISSN:18235-2016 \\ EFFECT OF HEALTH EDUCATION GUIDELINES TO PREVENT COMPLICATIONS ASSOCIATED THERAPEUTIC CARDIAC CATHETERIZATION AT SPECIALIZED MEDICAL HOSPITAL OF MANSOURA
}

\author{
${ }^{1}$ Fatma Abdel-Halim Mostafa, ${ }^{2}$ WafaaIsmailSherif, \\ and $^{3}$ Amira Ahmed Hassanin. \\ ${ }^{1}$ Clinical instructor ${ }^{2,3}$ Assist Prof.of Medical-Surgical Nursing \\ Department, Faculty of Nursing-Mansoura University \\ Email:fatmaelgohary2015@yahoo.com
}

\begin{abstract}
:
Cardiac catheterizations are common procedures among patients with cardiovascular diseases. Aim of the study: Assess the effect of health education guidelines to prevent complications associated therapeutic cardiac catheterization at Specialized Medical Hospital of Mansoura University. Method: A quasi-experimental research designwas utilized to accomplish this study. Subjects: included 75 patients undergoing therapeutic cardiac catheterization who admitted in the cardiac catheterization unit. Tools: Three tools were used for data collection; Patient's Assessment Sheet, assessment sheet of therapeutic cardiac catheterization procedure and assessment of patient's condition after the procedure and a questionnaire sheet for patient's health educational needs. Results: The study revealedbefore implementing the health education guidelines, $(92.0 \%)$ of the patients had poor total knowledge score level. On other hand, $(53.4 \%)$ of patients had good total knowledge score level while, only $(10.6 \%)$ of patients had poor total knowledge score levelafter implementing the health education guidelines. There was a statistical significant difference $(\mathbf{p}<\mathbf{0 . 0 5})$ between patient'stotal knowledge score levels and patient's total habits after implementing health education guidelines. Recommendations: Reinforcing follow-up education that focus on lifestyle modification for patient with therapeutic cardiac catheterization in outpatient clinics.
\end{abstract}

Key words: Health Education, Guidelines, Complications, Therapeutic Cardiac

Catheterization.

\section{Introduction:}

Although several methods are used for diagnosis and treatment of heart diseases such as chest X-ray, electrocardiogram and intravascular ultrasound, cardiac catheterization is the most definitive test in the diagnosis of heart disease; it may include studies of the right or left side of the heart and the coronary $\operatorname{arteries}^{(8,18)}$.
Cardiac catheterization is a highly accurate diagnostic procedure; it shows defects in the heart chambers, the valves, and coronary arteries.

Like any procedure, cardiac catheterization and coronary angiography have many complications. The most common complications following cardiac 
catheterization are allergic reaction, Infection, bleeding at the catheter insertion site, hematoma, retroperitoneal hematoma pseudoaneurysm, arterial occlusion, arteriovenous fistula, and other complications which in turn are associated with increased morbidity, mortality and

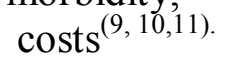

Patients undergoing cardiac catheterization have physical, psychological, educational and social needs before cardiac catheterization. These needs involve preparation of the insertion site, a trusting relationship with the nurse, relief patients and family anxiety and information about cardiac catheterization procedure, risks and benefits. Moreover, provision of effective educational programs for patients prior to cardiac catheterization such as written instructions ${ }^{(17) .}$

\section{Aim of study:}

The aim of the present study was to assess the effect of health education guidelines to prevent complications associated therapeuticcardiac

catheterization at Specialized Medical Hospital of Mansoura University in Dakahlia Governorate.

\section{Research question:}

1- Are patients have lack of knowledge regarding preparation of cardiac

catheterization?

2- Are patients have lack of knowledge regarding postcardiac catheterization self careand home care?

3- Is there relation between patient's knowledge and patient's habits?

\section{Materials \& Method}

\section{Study Design:}

A quasi-experimental research design was utilized to accomplish this study.

\section{Setting:}

This study was carried out in Cardiac Catheterization Unit in Medical Specialized Hospital at Mansoura University, in Dakahlia Governorate

\section{Subjects}

The subjects of the study included 75 patients who were admitted in the previously mentioned setting and were fulfilling the following criteria:

- Aged from 18 to less than 60, both sexes (male and female), undergoing therapeutic cardiac catheterization, and free from any another chronic diseases.

-Patients were excluded if they were having; only diagnostic cardiac catheterization, an infected wound, bleeding tendency, recent 
cerebrovascular accident, bronchial asthma, and chronic disease such as un controlled diabetes mellitus.

\section{Tools:}

The following three tools were modified by the researcher to collect the data of the study based upon reviewing related literature:-

\section{Tool I: Patient's Assessment Sheet:}

It was developed by the researcher to collect personal data about the patients, it consists of two parts:-

\section{Part 1:-}

It was concerned with sociodemographic data of patients as age, sex, occupation, marital status, level of education and residence.

\section{Part 2:-}

It was concerned with medical history and health condition of the patients and includes:

1- Patient's history and health condition such as history of previous diseases, onset of cardiovascular disease, present complaint as chest pain and its quality, dyspnea, excessive sweating and fainting, current medication and smoking

2- Laboratory investigations that were recorded in the patient's record and it included complete blood count, bleeding time, clotting time, platelet count andprothrombine time

3- Patient's habits: itincluded

a- Dietary habits ( 10 items)

b- Daily physical activities (6 items).

\section{Tool II:}

This tool was designed to assess therapeutic cardiac catheterization procedure itself and to assess patient's condition after the procedure, it was developed and modified by the researcher based on reviewing recent literature, and it was divided into two parts:-

\section{Part 1:}

\section{Assessment of therapeutic cardiac catheterization procedure}

This tool included the duration of procedure, type of therapeutic procedure, puncture site and catheter size.

\section{Part 2:}

\section{Assessment for patient after cardiac catheterization procedure}

It was designed to assess patient's condition after cardiac catheterization such as assessment of the limb for site of insertion which included (peripheral pulse, temperature, color and capillary refill),type of dressing, duration of manual pressure, degree of bed elevation, and onset of oral intake. 
Also it included time of turning in bed, time of ambulation and occurrence of complications.

\section{Tool III: Questionnaire sheet of patient's health educational needs}

This tool was modified by the researcher based on recent literaturefor the purpose of assessment of patient's health educational needs before and after the cardiac catheterization procedure, and was divided two parts:-

Part 1: Pre - catheterization phase (12 items), it was designed to assess patient's health educational needs before cardiac catheterization procedure (preparation) such as definition of cardiac catheterization, doing shaving, having a shower, fasting period, training for breathing exercise, giving informed consent, taking prescribed drugs and cessation of smoking

Part 2: post - catheterization phase (36 items), it was designed to assess patient's health educational needs after cardiac catheterization procedure such as Average number for having glasses of water, Duration of manual pressure, allowed physical activity, healthy diet regimen, allowed activity and possible complications.

\section{Method:}

\section{Administrative design:}

An official approval to carry out the study was obtained from the Dean of Faculty of Nursing and the head of the Specialized Medical Hospital of Mansoura. The researcher introduced herself to all patients and the aim of the study was explained prior their participation to obtain their acceptance and cooperation as well as their verbal consent.

\section{Ethical Considerations of the study}

Ethical approval was obtained from Research Ethics Committee at the Faculty of Nursing and Mansoura University. Consent was obtained from each patient included in the study after clarification of the purpose of the study. Anonymity, privacy, safety and confidentiality were absolutely assured throughout the whole study. The patients were informed about their rights to refuse participation or withdraw from the study at any time.

\section{Operational Design}

The operational design is the second phase of the study. This design included description of preparatory phase, pilot study and field work which include assessment phase, planning phase, implementation phase, and evaluation phase. 
Preparatory phase:

It included reviewing of the past and current local and international related literature and theoretical knowledge of the various aspects of the study using books, articles, internet, periodicals and magazines to develop the tools of data collection.

\section{Pilot study:}

The developed guidelines were applied on $10 \%$ of the study subjects ( 8 patients) before starting the data collection. This was done in order to test the clarity, relevance of the data collection tools and to estimate the time needed to complete the tools. According to the results of pilot study, the necessary modifications of some items were done to have more applicable tools for data collection. The patients who included in the pilot study were excluded from the main study group.

\section{Field work:}

- The actual field work of the study conducted for 7 months period, started in October 2013 and ended in April 2014 to collect the data needed for the study..

- Health education guidelines were carried out through four phases "assessment phase, planning phase (development of guidelines), implementation of guidelines, and evaluation phase".
Phase one: "Assessment Phase".

During this phase the researcher met every patient included in the study after introducing herself to the patient, a full explanation of the aim and method of the study was done to obtain their acceptance and cooperation as well as their verbal consent. It was carried out by the researcher for all study subject to collect baseline data to assess their knowledge.

\section{Phase two: "Planning Phase" \\ (Development of Health Education Guidelines to Prevent Complications Associated Cardiac catheterization)}

A colored booklet was developed by the researcher based on reviewing the related literature. It is written in a simple Arabic language and supplemented by photos and illustrations to help the patient understanding of the content.

\section{General objectives:}

The main objective of these guidelines is to:

At the end of this study, the patients are expected to be able to demonstrate different aspects of care for themselves along the phases of cardiac catheterization

\section{Specific objectives:}

1- Help for minimizing vascular complications following cardiac catheterization.

2- Enhance post cardiac catheterization recovery. 


\section{Phasethree: "Implementation Phase"}

- During this phase, the developed colored booklet in Arabic format was applied for each patient in the study group to attract his attention, motivate him, and help for reviewing at home and support teaching and practice at home.

- This booklet was included seven main parts and it was applied in 3 sessions.

- Each session took about 30 to 40 minutes and taking in consideration the attention span of the patient.

- Three sessions per week were applied for each patient.

\section{Phase four: "Evaluation Phase"}

- During this phase patients included in the study were evaluated to test the effectiveness of the implementation of health education guidelines to prevent complications associated therapeutic cardiac catheterization using data collection tools.

- Each patient in study group was interviewed after one month from discharge (post-test) after applying the instructional guidelines sessions to assess his knowledge and current habits

using the study tools $\boldsymbol{I}, \boldsymbol{I I I}$.

\section{Statistical design:}

Data entry and analysis were performed using SPSS statistical package version 16. Categorical variables were expressed as number and percentage while continuous variables were expressed as (mean $\pm \mathrm{SD})$. Chi-Square $\left(x^{2}\right)$ was used to test the association between row and column variable of qualitative data. Paired t-test was conducted to evaluate the impact of time on the mean of continuous variable.

Pearson's correlation coefficient was used to test correlation between variables. For all above mentioned statistical tests done, the threshold of significance is fixed at $5 \%$ level ( $\mathrm{p}$ value). $\mathrm{P}$ value of $<$ 0.05 and of $<0.001$ indicates a significant result and a high significant result respectively while $\mathrm{p}$ value $>0.05$ indicates non significant result.

\section{Results:}

The results of the present study were categorized into 3 main parts as following:

1. Assessment part.

2. Effect of implementing guidelines part.

Correlation part. 


\section{Result:}

Table (1): Socio-demographic characteristics of the study subjects:

\begin{tabular}{|c|c|c|c|}
\hline \multirow{2}{*}{\multicolumn{2}{|c|}{ Personal Data }} & \multicolumn{2}{|c|}{ Total $N=75$} \\
\hline & & \multirow{2}{*}{$\begin{array}{l}\text { No. } \\
0\end{array}$} & \multirow{2}{*}{$\begin{array}{ll} & \% \\
0 & \end{array}$} \\
\hline Age & $18-30$ & & \\
\hline & $31-40$ & 17 & $22.7 \%$ \\
\hline & $41-50$ & 40 & $53.3 \%$ \\
\hline & $51-<60$ & 18 & $24 \%$ \\
\hline \multirow[t]{2}{*}{ Gender } & Male & 64 & $85.3 \%$ \\
\hline & Female & 11 & $14.7 \%$ \\
\hline \multirow[t]{4}{*}{ Education } & Illiterate & 33 & $44 \%$ \\
\hline & Primary/Preparatory & 26 & $34.6 \%$ \\
\hline & Secondary & 11 & $14.7 \%$ \\
\hline & University & 5 & $6.7 \%$ \\
\hline \multirow[t]{2}{*}{ Occupation } & Currently working & 58 & $77.3 \%$ \\
\hline & Not working/Retired & 17 & $22.7 \%$ \\
\hline \multirow[t]{4}{*}{ Marital status } & Married & 55 & $73.3 \%$ \\
\hline & Single & 3 & $4.0 \%$ \\
\hline & Divorced & 6 & $8.0 \%$ \\
\hline & Widow & 11 & $14.7 \%$ \\
\hline
\end{tabular}

Table 1: Illustrates that more than half (53.3\%) of patients were from 41 to 50 years old and the majority $(85.3 \%)$ of the patients were males. As regards the level of education, more than two fifths $(44 \%)$ of patients were illiterate while only $(6.7 \%)$ of them were university level. Concerning the occupation, above three quarters $(77.3 \%)$ of them were working and $(73.3 \%)$ of them were married.

Figure (1): Classification of patients according to their Residence:

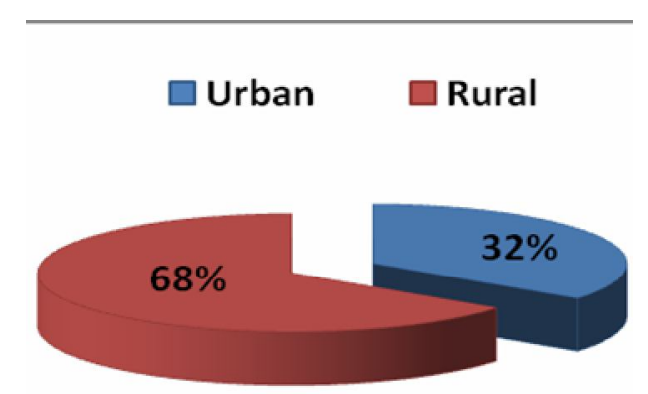

Figure (1) demonstrates that almost more than two thirds (68\%) of patients were from rural areas, while (32\%) of them were from urban areas. 
Fatma Abdel-Halim Mostafa et. al.

Table (2): Number and percentage distribution of studied patients according to their medical history:

\begin{tabular}{|l|c|c|}
\hline \multirow{2}{*}{ Items } & \multicolumn{2}{c|}{ Total N=75 } \\
\cline { 2 - 3 } & No. & \% \\
\hline Hypertension & 30 & $40 \%$ \\
\hline Diabetes Mellitus & 33 & $44 \%$ \\
\hline Renal problems & 4 & $5.3 \%$ \\
\hline Liver disease & 5 & $6.7 \%$ \\
\hline Rheumatic heart diseases & 2 & $2.7 \%$ \\
\hline Stroke & 0 & 0 \\
\hline Bleeding & 0 & 0 \\
\hline Hypercholesterolemia & 11 & $14.7 \%$ \\
\hline Obesity & 19 & $25.3 \%$ \\
\hline
\end{tabular}

Table (2) clarifies that two fifths (40\%) of patients were hypertensive and also $(44 \%)$ of them had diabetes mellitus, while only $(5.3 \%)$ of them had renal problems and $(6.7 \%)$ had liver disease. Slightly more than one quarter $(25.3 \%)$ of the patients had obesity. On the other hand, only $(2.7 \%)$ of patients had rheumatic heart diseases.

Figure (2): Patient classification according to their knowledge level regarding pre and post cardiac catheterization phase before implementing health education guidelines:

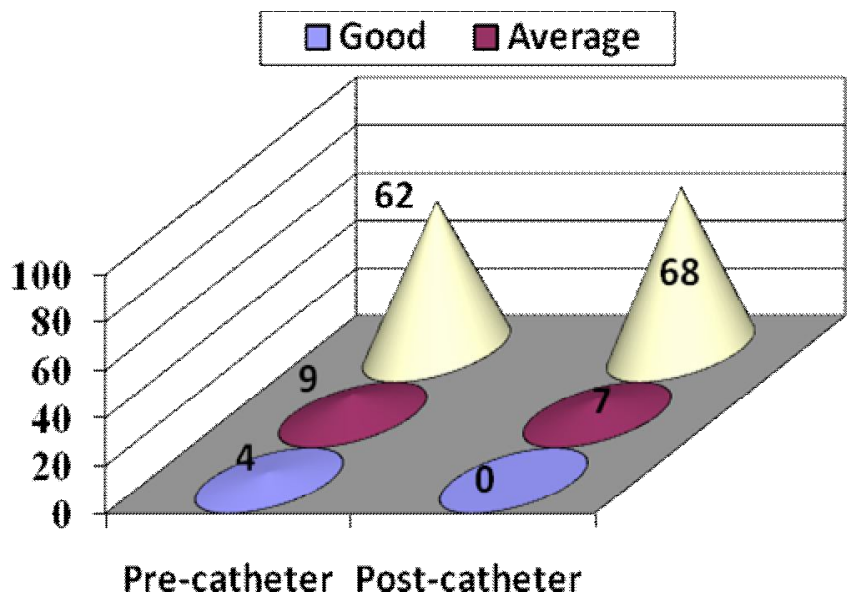

Figure (2) reveals that before implementing the health education guidelines, the majority $(82.7 \%)$ of patients had poor knowledge level regarding pre-cardiac catheterization phase (preparation) and also the

$(90.6 \%)$ of them had poor knowledge level regarding post cardiac catheterization phase. 
Figure (3): Patients classification according to their knowledge level regarding pre and post cardiac catheterization phase after implementing health education guidelines:

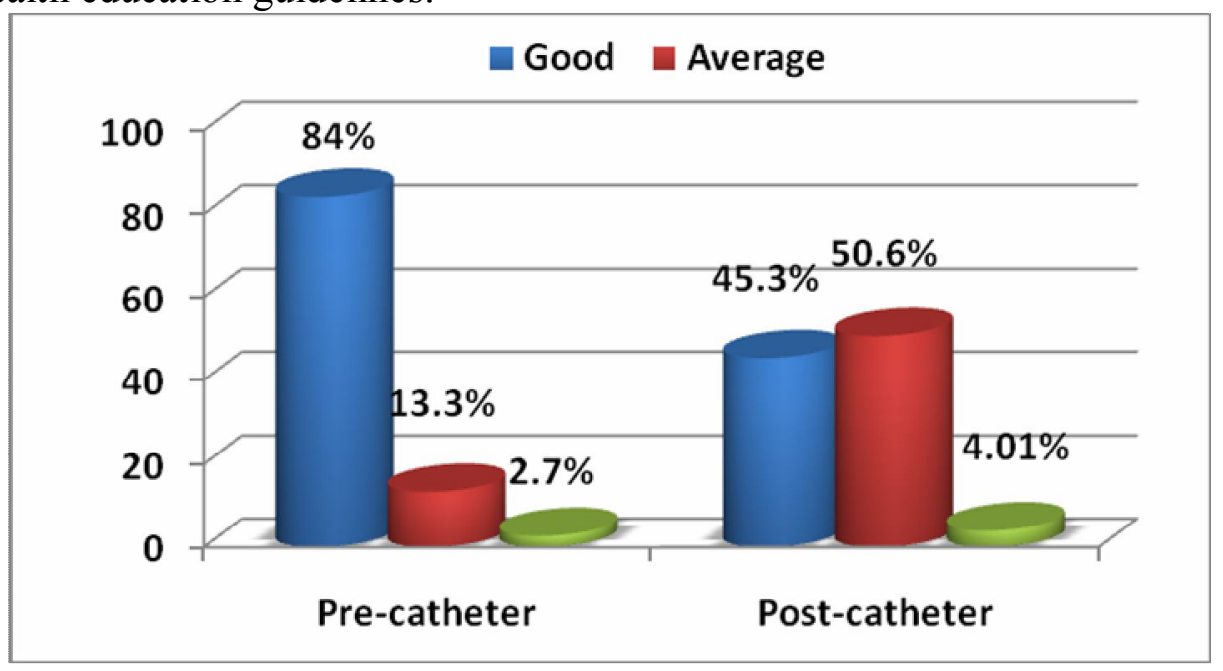

Figure (3) reveals that after implementing the health education guidelines, the majority $(84 \%)$ of patients had good knowledge level regarding precardiac catheterization phase (preparation). While only $(2.7 \%)$ had poor knowledge level regarding pre-cardiac catheterizationphase (preparation). On the other hand, slightly more than half $(50.6 \%)$ of patients had an average knowledge level regarding post cardiac catheterization phase

Table (3): Distribution of patients' Total Knowledge Score Levels regarding cardiac catheterization (preparation and post cardiac catheterization):

\begin{tabular}{|l|c|c|c|c|}
\hline \multirow{2}{*}{ Level of knowledge } & \multicolumn{4}{|c|}{ Total Knowledge } \\
\cline { 2 - 5 } & \multicolumn{2}{|c|}{ Pre-Test } & \multicolumn{2}{c|}{ Post-Test } \\
\cline { 2 - 5 } & No. & \% & No. & \% \\
\hline Good & - & - & 40 & $53.4 \%$ \\
\hline Average & 6 & $8.0 \%$ & 27 & $36.0 \%$ \\
\hline Poor & 69 & $92.0 \%$ & 8 & $10.6 \%$ \\
\hline Total & $\mathbf{7 5}$ & $\mathbf{1 0 0 \%}$ & $\mathbf{7 5}$ & $\mathbf{1 0 0 \%}$ \\
\hline
\end{tabular}

Table (3) illustrates that the majority $(92.0 \%)$ of the patients had poor total knowledge score level, while the minority $(8.0 \%)$ of them had an average total knowledge score level before implementing the health education guidelines (Pre-test). Concerning the post-test, more than half $(53.4 \%)$ of patients had good total knowledge score level while, only $(10.6 \%)$ of patients had poor total knowledge score level 
Table (4): Correlation between patients' total knowledge score levels and socio-demographic characteristics before health education guidelines:

\begin{tabular}{|c|c|c|c|c|c|c|c|c|c|c|}
\hline \multirow{2}{*}{ Items } & \multicolumn{2}{|c|}{$\begin{array}{l}\text { Good } \\
(n=0)\end{array}$} & \multicolumn{2}{|c|}{$\begin{array}{c}\text { Average } \\
(n=6)\end{array}$} & \multicolumn{2}{|c|}{$\begin{array}{c}\text { Poor } \\
(n=69)\end{array}$} & \multicolumn{2}{|c|}{$\begin{array}{c}\text { Total } \\
(n=75)\end{array}$} & $\mathbf{X}^{2}$ & $\begin{array}{c}\text { P. } \\
\text { Value }\end{array}$ \\
\hline & No. & $\%$ & No. & $\%$ & No. & $\%$ & No. & $\%$ & & \\
\hline $\begin{array}{l}\text { 1- Age : } \\
31-40 \\
41-50 \\
51-60\end{array}$ & $\begin{array}{l}- \\
- \\
-\end{array}$ & $\begin{array}{l}- \\
- \\
-\end{array}$ & $\begin{array}{l}3 \\
3 \\
-\end{array}$ & $\begin{array}{l}50 \\
50 \\
- \\
\end{array}$ & $\begin{array}{l}14 \\
37 \\
18\end{array}$ & $\begin{array}{l}20.3 \\
53.6 \\
26.1\end{array}$ & $\begin{array}{l}17 \\
40 \\
18\end{array}$ & $\begin{array}{l}22.7 \\
53.3 \\
24.0\end{array}$ & 3.72 & 0.155 \\
\hline $\begin{array}{l}\text { 2- Gender: } \\
\text { Male } \\
\text { Female }\end{array}$ & - & - & $\begin{array}{l}6 \\
0 \\
\end{array}$ & $\begin{array}{c}100 \\
0 \\
\end{array}$ & $\begin{array}{l}58 \\
11 \\
\end{array}$ & $\begin{array}{l}84.1 \\
15.9 \\
\end{array}$ & $\begin{array}{l}64 \\
11 \\
\end{array}$ & $\begin{array}{l}85.3 \\
14.7 \\
\end{array}$ & 1.12 & 0.290 \\
\hline $\begin{array}{l}\text { 3-Education: } \\
\text { Illiterate } \\
\text { Primary/Prep } \\
\text { Secondary } \\
\text { University }\end{array}$ & $\begin{array}{l}- \\
- \\
- \\
-\end{array}$ & $\begin{array}{l}- \\
- \\
- \\
-\end{array}$ & $\begin{array}{l}2 \\
1 \\
1 \\
2\end{array}$ & $\begin{array}{l}33.3 \\
16.7 \\
16.7 \\
33.3\end{array}$ & $\begin{array}{l}31 \\
25 \\
10 \\
3 \\
\end{array}$ & $\begin{array}{c}44.9 \\
36.2 \\
14.5 \\
4.3\end{array}$ & $\begin{array}{c}33 \\
26 \\
11 \\
5\end{array}$ & $\begin{array}{c}44.0 \\
34.7 \\
14.7 \\
6.7\end{array}$ & 11.7 & $\begin{array}{c}* \\
<0.05\end{array}$ \\
\hline $\begin{array}{l}\text { 4-Occupation } \\
\text { Working } \\
\text { Not working }\end{array}$ & - & $\begin{array}{l}- \\
-\end{array}$ & $\begin{array}{l}5 \\
1\end{array}$ & $\begin{array}{l}83.3 \\
16.7\end{array}$ & $\begin{array}{l}53 \\
16\end{array}$ & $\begin{array}{l}76.8 \\
23.2 \\
\end{array}$ & $\begin{array}{l}58 \\
17 \\
\end{array}$ & $\begin{array}{l}77.3 \\
22.7 \\
\end{array}$ & 0.13 & 0.714 \\
\hline $\begin{array}{l}\text { 5-Residence: } \\
\text { Rural } \\
\text { Urban }\end{array}$ & - & - & $\begin{array}{l}2 \\
4\end{array}$ & $\begin{array}{l}33.3 \\
66.7\end{array}$ & $\begin{array}{l}49 \\
20\end{array}$ & $\begin{array}{l}71.0 \\
29.0\end{array}$ & $\begin{array}{l}51 \\
24\end{array}$ & $\begin{array}{l}68.0 \\
32.0\end{array}$ & 13.6 & $\begin{array}{l}* \\
0.03\end{array}$ \\
\hline
\end{tabular}

Not Significant $P>0.05$

Significant $<0.05$

Table (4) clarifies that before implementing the health education guidelines, there were statistical significant difference $(\mathbf{p}<\mathbf{0 . 0 5})$ between patient's total knowledge score levels and patient's level of education and also between patient's total knowledge score levels and patient's residence. 
Table (5): Correlation between patients' total knowledge score levels and socio-demographic characteristics after implementing health education guidelines:

\begin{tabular}{|c|c|c|c|c|c|c|c|c|c|c|}
\hline \multirow[b]{2}{*}{ Items } & \multicolumn{2}{|c|}{$\begin{array}{c}\text { Good } \\
(n=40)\end{array}$} & \multicolumn{2}{|c|}{$\begin{array}{c}\text { Average } \\
(n=27)\end{array}$} & \multicolumn{2}{|c|}{$\begin{array}{c}\text { Poor } \\
(n=8)\end{array}$} & \multicolumn{2}{|c|}{$\begin{array}{c}\text { Total } \\
(n=75)\end{array}$} & $\mathbf{X}^{2}$ & $\begin{array}{c}\text { P. } \\
\text { Value }\end{array}$ \\
\hline & No. & $\%$ & No. & $\%$ & No. & $\%$ & No. & $\%$ & & \\
\hline $\begin{array}{l}\text { 1- Age : } \\
31-40 \\
41-50 \\
51-60\end{array}$ & $\begin{array}{l}11 \\
19 \\
10\end{array}$ & $\begin{array}{c}27.5 \\
47.5 \\
25 \\
\end{array}$ & $\begin{array}{c}5 \\
18 \\
4 \\
\end{array}$ & $\begin{array}{l}18.5 \\
66.7 \\
14.8 \\
\end{array}$ & $\begin{array}{l}1 \\
3 \\
4\end{array}$ & $\begin{array}{c}12.5 \\
37.5 \\
50\end{array}$ & $\begin{array}{l}17 \\
40 \\
18\end{array}$ & $\begin{array}{c}22.6 \\
53.4 \\
24 \\
\end{array}$ & 4.305 & 0.366 \\
\hline $\begin{array}{l}\text { 2- Gender: } \\
\text { Male } \\
\text { Female }\end{array}$ & $\begin{array}{c}35 \\
5 \\
\end{array}$ & $\begin{array}{l}87.5 \\
12.5 \\
\end{array}$ & $\begin{array}{c}23 \\
4 \\
\end{array}$ & $\begin{array}{l}85.1 \\
14.9 \\
\end{array}$ & $\begin{array}{l}6 \\
2 \\
\end{array}$ & $\begin{array}{l}75 \\
25\end{array}$ & $\begin{array}{l}64 \\
11 \\
\end{array}$ & $\begin{array}{l}85.3 \\
14.7 \\
\end{array}$ & 0.008 & 0.996 \\
\hline $\begin{array}{l}\text { 3-Education: } \\
\text { Illiterate } \\
\text { Primary/Prep } \\
\text { Secondary } \\
\text { University }\end{array}$ & $\begin{array}{c}15 \\
11 \\
10 \\
4\end{array}$ & $\begin{array}{c}37.5 \\
27.5 \\
25 \\
10 \\
\end{array}$ & $\begin{array}{c}12 \\
13 \\
1 \\
1 \\
\end{array}$ & $\begin{array}{c}44.5 \\
48.1 \\
3.7 \\
3.7 \\
\end{array}$ & $\begin{array}{l}6 \\
2 \\
0 \\
0\end{array}$ & $\begin{array}{c}75 \\
25 \\
0 \\
0 \\
\end{array}$ & $\begin{array}{c}33 \\
26 \\
11 \\
5\end{array}$ & $\begin{array}{c}44 \\
34.7 \\
14.6 \\
6.7 \\
\end{array}$ & 28.68 & $<0.001$ \\
\hline $\begin{array}{l}\text { 4-Occupation } \\
\text { Working } \\
\text { Not working }\end{array}$ & $\begin{array}{c}31 \\
9\end{array}$ & $\begin{array}{l}80.7 \\
19.3\end{array}$ & $\begin{array}{l}21 \\
6\end{array}$ & $\begin{array}{l}73.1 \\
26.9\end{array}$ & $\begin{array}{l}6 \\
2\end{array}$ & $\begin{array}{l}75 \\
25\end{array}$ & $\begin{array}{l}58 \\
17\end{array}$ & $\begin{array}{l}77.3 \\
22.7\end{array}$ & 0.633 & 0.729 \\
\hline $\begin{array}{l}\text { 5-Residence: } \\
\text { Rural } \\
\text { Urban } \\
\end{array}$ & $\begin{array}{l}33 \\
7 \\
\end{array}$ & $\begin{array}{l}82.5 \\
17.5 \\
\end{array}$ & $\begin{array}{l}13 \\
14 \\
\end{array}$ & $\begin{array}{l}48.1 \\
51.9 \\
\end{array}$ & $\begin{array}{l}5 \\
3 \\
\end{array}$ & $\begin{array}{l}62.5 \\
37.5 \\
\end{array}$ & $\begin{array}{l}51 \\
24 \\
\end{array}$ & $\begin{array}{l}68 \\
32 \\
\end{array}$ & 2.652 & 0.265 \\
\hline
\end{tabular}

Not Significant $P>0.05 \quad$ Significant $<0.05$

\section{Highly Significant $P<0.001$}

Table (5) clarifies that after implementing the health education guidelines, there was a highly statistical significant difference $(\mathbf{p}<\mathbf{0 . 0 0 1})$ between patient's total knowledge score levels and patient's level of education

Table (6): Correlation between total knowledge score (good, average, poor) and total habits (acceptable, unacceptable) before implementing health education guidelines:

\begin{tabular}{|c|c|c|c|c|c|c|c|c|c|c|}
\hline \multirow{2}{*}{$\begin{array}{l}\text { Anowledge } \\
\text { Total habits }\end{array}$} & \multicolumn{2}{|c|}{$\begin{array}{c}\text { Good } \\
(\text { no. }=0)\end{array}$} & \multicolumn{2}{|c|}{$\begin{array}{c}\text { Average } \\
(\text { no. }=6)\end{array}$} & \multicolumn{2}{|c|}{$\begin{array}{c}\text { Poor } \\
(\text { no. }=69)\end{array}$} & \multicolumn{2}{|c|}{$\begin{array}{l}\text { Total } \\
n=75\end{array}$} & \multirow[t]{2}{*}{$\mathbf{X}^{2}$} & \multirow[t]{2}{*}{$\begin{array}{c}\text { P. } \\
\text { value }\end{array}$} \\
\hline & No. & $\%$ & No. & $\%$ & No. & $\%$ & No. & $\%$ & & \\
\hline \multirow{2}{*}{ Acceptable } & - & - & 4 & 66.7 & 2 & 2.8 & 6 & 8 & \multirow[b]{2}{*}{26.67} & \multirow[t]{2}{*}{$<0.001$} \\
\hline & - & - & 2 & 33.3 & 67 & 97.2 & 69 & 92 & & \\
\hline
\end{tabular}

Table (6) reveals that there was a highly statistical significant difference $(\boldsymbol{p}<\mathbf{0 . 0 0 1})$ between patient's total knowledge score levels and patient's total habits before implementing health education guidelines. 
Table (7): Relation between patient's total knowledge score (good, average, poor) and patient's total habits (acceptable, unacceptable) after implementing health education guidelines:

\begin{tabular}{|c|c|c|c|c|c|c|c|c|c|c|}
\hline \multirow{2}{*}{ Total habits } & \multicolumn{2}{|c|}{$\begin{array}{c}\text { Good } \\
\text { (no.=40) }\end{array}$} & \multicolumn{2}{|c|}{$\begin{array}{l}\text { Average } \\
(\text { no. }=27)\end{array}$} & \multicolumn{2}{|c|}{$\begin{array}{c}\text { Poor } \\
(\text { no. }=8)\end{array}$} & \multicolumn{2}{|c|}{$\begin{array}{l}\text { Total } \\
n=75\end{array}$} & \multirow[t]{2}{*}{$\mathbf{X}^{2}$} & \multirow[t]{2}{*}{$\begin{array}{c}P . \\
\text { value }\end{array}$} \\
\hline & No. & $\%$ & & & & & & & & \\
\hline & 32 & 80 & 17 & 63 & 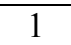 & 12 & 50 & 66.7 & & \\
\hline able & 8 & 20 & 10 & 37 & 7 & 87.5 & 25 & 33.3 & 22.12 & $<0.05$ \\
\hline
\end{tabular}

Table (7) describes that there was a statistical significant difference $(\mathbf{p}<\mathbf{0 . 0 5})$ between patient's total knowledge score levels and patient's total habits after implementing the health education guidelines

\section{Discussion:}

The number of cardiovascular invasive procedures has significantly increased worldwide over the last years. Diagnostic and therapeutic cardiac catheterizations will continue to be a common procedure among coronary artery disease patients.

The current study was performed to assess the effect of health education guidelines to prevent complications associated therapeutic cardiac catheterization at Specialized Medical Hospital of Mansoura University.

The results of this study show that more than half of the patients were between the age of 41 and 50 years old. This is in agreement with ${ }^{(1)}$ findings that the majority of patients were between the age of 40 and 50 years old.

This result is in contrast with ${ }^{(2,23)}$ who emphasized that more than half of patients were at age 50 and 60 years old. ${ }^{(3,19)}$ reported that old age independent non modifiable risk factors increase the frequency and severity of coronary heart diseases.

As regards to sex, the findings of the present study illustrate that the great majority of the studied patients were males while minority were females. This was in line with $(2,20)$ who stated that heart diseases are more prevalent in males.

This is in discordance with ${ }^{(4)}$ who emphasized that women appear to be at increased risk for CADthan men because the risk of the women increases significantly at menopause.

In relation to the study subject's educational level, the results reveal that slightly more than one third were in primary school level and the minority attended secondary school. This is consistent with ${ }^{(2)}$ findings that slightly more than two fifths percent of the patients were in the level of primary school studies. This is in disagreement with ${ }^{(22)}$ whose findings emphasized that 
the majority of his study subjects had secondary education level.

With respect to occupation, the present study illustrates that more than three quarters of the sample were workers. This may be related to their daily work duties, work problems and may suffer from physical and psychological stressors. In agreement with this study result, ${ }^{(1)}$ emphasized that the majority of patients undergoing cardiac catheterization in her study were employed. ${ }^{(5)}$ disagreed with this finding whose study showed that more than one half of study subjects were unemployed.

In relation to the medical history, the results demonstrate that two fifths of the patients had hypertension; this coincided with ${ }^{(21)}$ whose study revealed that more than half of patients had hypertension. Also current study shows that more than two fifths of studied patients had diabetes mellitus. This is congruent with ${ }^{(1)}$ who stated that the majority of the patients with CAD were diabetic.

In the present study, a few number of patients had knowledge about post catheterization care before implementing the guidelines. ${ }^{(16)}$ Found that post cardiac catheterization instructions are necessary to ensure safe and effective care to patients after cardiac catheterization.

Concerning patients' knowledge after implementing the health education guidelines, more than half of patients had good total knowledge score level. This is congruent with ${ }^{(12)}$ who mentioned that most studies that measured intervention effect on knowledge showed a significant improvement in knowledge.

The findings of this study reveal that there were statistical significant difference $(p<0.05)$, $(p<0.001)$ between patient's total knowledge score levels and patient's level of education before and after implementing the health education guidelines.In agreement with this result, ${ }^{(24)}$ mentioned that the total knowledge score was associated to educational level.

(15) disagreed with these findings and illustrated that there was no significant differences in knowledge score regarding therapeutic cardiac catheterization and level of education and married participants were more knowledge about therapeutic cardiac catheterization than those who were single $(p=0.026)$.

In the current study, the results shows that there was a highly statistical significant difference $(p<0.001)$ between patient's total knowledge score levels and patient's total habits before implementing health education guidelines. Also,there was a statistical significant difference $(p<0.05)$ between patient's total knowledge score levels and 
Fatma Abdel-Halim Mostafa et. al.

patient's total habits after implementing the health education guidelines.

This is certainly due to the effect of the educational guidelines which improved patient's knowledge and habits. ${ }^{(25)}$ Findings coincided with this study and showed there was an association between poor knowledge and lacking of healthy practice.

In contrary with the current result, ${ }^{(13,14)}$ found that there was no association between knowledge about coronary artery disease and interventions like (angioplasty) and increased physical activity.

\section{Conclusion:}

From the findings of the current study, the following can be deduced:

Before implementing the health education guidelines, the majority of patients had poor knowledge level regarding precardiac catheterization phase (preparation) and also regarding post cardiac catheterization phase. While after implementing the health education guidelines, the majority of patients had good knowledge level regarding precardiac catheterization phase (preparation). And more than half of patients had an average knowledge level regarding post cardiac catheterization phase.

As regard to the effect of implementing health education guidelines, the majority of the patients had poor total knowledge score level before implementing the health education guidelines (Pretest).While, during the post-test, more than half of patients had good total knowledge score level.

There was a highly statistical significant difference $(\boldsymbol{p}<\mathbf{0 . 0 0 1})$ between patient's total knowledge score levels and patient's total habits before implementing health education guidelines. Furthermore, there was a statistical significant difference $\quad(\boldsymbol{p}<\mathbf{0 . 0 5}) \quad$ between patient's total knowledge score levels and patient's total habits after implementing the health education guidelines.

\section{Recommendation:}

Based upon the result of the current study, the following recommendations can be suggested:

- Additional studies are required to reduce the risk of complications and increase safety for patients undergoing cardiac catheterization.

- Additional study is needed to provide cardiac rehabilitation program for cardiac patients with therapeutic cardiac catheterization.

- Assessment of the effect of health education program on anxiety level for patients undergoing therapeutic cardiac catheterization before, during and after procedure.

- Reinforcing follow-up education in outpatient clinics. 
- Post-procedural education for patient undergoing therapeutic cardiac catheterization should include information on medication, resumption of activities post-discharge, complications and its management.

- Further research is needed to emphasize cardiac catheterization patient's needs (physical, psychological and health educational needs).

- Further study is required for developing subtler tools to assess comfort, satisfaction and anxiety for patients undergoing therapeutic cardiac catheterization before, during and after cardiac catheterization procedure.

\section{References:}

1. Elsayed H., (2010):

Developing Nursing Care

Guidelines for patients

Undergoing Cardiac

Catheterization based on their needs, MSC Thesis, Faculty of Nursing. Alexandria University: PP. 51-57.

2. Vardanjani S., Fanisaberi L., Shahraki F., Khalilzadeh A., Vardanjani A., and Dehkordi F., ( 2013): The Effect of Faceto-Face Education and Educational Booklet on Heart Health Indexes of the Hospitalized Patients with Myocardial Infarction, Journal of Nursing research and practice. 8 pages.

3. Chanudet X., Bonnevie L., and Bauduceau (2007):

Coronary heart diseases and cardiovascular anatomic neuropathy in elderly diabetic, Journal of Cardiology, 33(1):PP.19-31.

4. Ameen D., (2008): Factors affecting quality of life for patients with coronary artery disease, Unpublished Master Thesis, Faculty of Nursing. Ain Shams University: PP.40-57.

5. Gendy J., Mahrous F., and EI ghatey A., (2013): Guidelines for the Factors Affecting Compliance of Patients with Coronary Artery Bypass Graft toward Therapeutic Regimen. Journal of American Science; 9(12):PP. 729-742.

6. Gurm H., and Kooiman J., (2014):Interventional

Cardiology Clinics; Renal Complications in the catheterization Laboratory, Philadelphia. Elsevier Co., 3(3).

7. Bullock I., Clark D., and Malone J., (2012): Adult Nursing Practice; Using Evidence in Care. United Kingdom, Oxford University Press, 1st ed.: PP. 93-97.

8. Edmond J., and Strange J., (2008): Introduction to cardiac catheterization, Baumbach, British Journal of Cardiac Nursing; 3(7): PP. 398-406. 
Fatma Abdel-Halim Mostafa et. al.

9. Bhatty Sh., Cooke R., Shetty R., and Jovin I., (2013): Vascular Access Complications: Diagnosis and Management, Current Treatment Options in Cardiovascular Medicine; 3. (4): PP. 503-514.

10. Jeremias A., and Brown D., (2010): Cardiac Intensive Care. Philadelphia. Elsevier Saunders. 2nd ed.: PP.559-563.

11. Thatcher J., (2008): Groin bleeds and other hemorrhagic complications of catheterization, Journal of American College of Cardiology; 16 (3).

12. Mensah

CY., HimmelfarbDC., (2012): Patient Education Strategies for Hospitalized Cardiovascular Patients: A Systematic Review, Journal of Cardiovascular Nursing, 27 (2): PP. 154-174.

13. Kayaniyil SH., Ardern CH., Winstanley J., Parsons C., BristerS,Paul O., Stewart D., and Grace SH., (2009): Degree and correlates of cardiac knowledge and awareness among cardiac inpatients. Available in PubMed Central Canada [2010 September 7]. Patient Education Counseling, Canada; 75(1): 99-107.

14. Kang Y., Yang IS., and Kim N., (2010): Correlates of Health Behaviors in Patients with Coronary Artery Disease, Asian
Nursing Research, 4(1):PP. 4554.

15. Lipsky S., Bohnen M., Barnhart J., (2010): The Impact of Sociodemographic Factors on Knowledge of Cardiac Procedures, Scientific Research, 1: PP. 229-232.

16. Hamel WJ., (2009): Femoral Artery Closure after Cardiac Catheterization. Journal of Critical Care Nurse; 29: PP. 3946.

17. Moser D., and Riegel B., (2008): Cardiac Nursing. Canada. Elsevier Saunders Co., 12th ed.: PP.339-343.

18. Ignatavicius D., and Workman M., (2013): Medical- Surgical Nursing: Patient-Centered Collaborative Care. United States of America. Elsevier Saunders Co., 7th ed.: PP.686-705.

19. Kant R., Sharma R., Singh B., and Mahajan (2007): Important determinant in affecting the level of serum apolipoprotein B and A1 in Indian population. Journal of Cardiology, (1).

20. Piva C.,Vaz E., Moraes M., Goldmeyer S., Linch G., NogueiraG.,and Souza D., (2014): Discomfort Reported by Patients After Cardiac Catheterization Using the Femoral or Radial Approaches, RevistaBrasileira de 
CardiologiaInvasiva,

22(1):PP.36-40.

21. Shabrawi M., (2010):

Frequency and risk factors of vascular complications

following coronary procedures via the femoral artery. MSC Thesis, Faculty of Medicine, Ain Shams University.

22. Yahya R., Muhamad R., Yusoff H., (2012): Association between Knowledge, Attitude and Practice on Cardiovascular Disease among Women in Kelantan, Malaysia, International Journal of Collaborative Research on Internal Medicine \& Public Health, 4(8):PP. 1507-1520.
23. Mahgoub A., (2013): Impact of Early Ambulation on Patients' Outcome Post Transfemoral Coronary Procedures, at Assiut University Hospital, Journal of Education and Practice; 4(28):PP. 22-32.

24. Seef S., Jeppsson A., Stafström S., (2013): What is killing? People's knowledge about coronary heart disease, attitude towards prevention and main risk reduction barriers in Ismailia, Egypt (Descriptive cross-sectional study). Pan African Medical Journal. ISSN 1937-8688. (15):137.

25. Jafary F, Aslam F, Mahmud H, Waheed A, Shakir M, Afzal A, et al. (2005): Cardiovascular health knowledge and behavior in patient attendants at four tertiary care hospitals in Pakistan - a cause for concern. Biomedcentral Public Health; 5(1):PP.124 